\title{
Helen Salisbury: What might we learn from the covid-19 pandemic?
}

\author{
Helen Salisbury GP
}

Oxford

Events are moving so quickly that whatever I write today (15 March) is likely to be out of date by the time it's printed. Last week most GPs realised that waiting for instructions was inappropriate, so we've radically rearranged and reprioritised our work. Perhaps the first lesson I've learnt is that it's OK to be brave about making disruptive decisions. Although I may get it wrong, doing nothing is likely to be riskier.

Looking ahead, old fashioned GPs like me may undergo a rapid conversion to remote consulting. Maybe we'll discover that more is possible than we imagined. We'll inevitably have to make important clinical decisions with less information than usual: we'll need to assess disease severity and work out treatment options without being able to examine our patient or measure pulse, blood pressure, respiratory rate, or oxygen saturation.

Stepping back from our previous busy-ness may help us prioritise in the future: are there things we stopped doing, with no obvious adverse consequences? Admittedly, it may be difficult to tell, in the confusion ahead.

We'll discover the robustness, or otherwise, of drug supply chains, with possible disruption to the manufacture and transport of medicines. Like most healthcare sectors, our local pharmacies are likely to be understaffed and overworked in the coming weeks.

Away from our surgeries, our world may become more starkly divided into people with too little to do and those with too much. While some are kicking their heels, self-isolating at home, the rest will be working all hours to fill the gaps and look after the growing number of ill patients. Significant numbers of people will be confined to base with their families-which may result in a baby boom next Christmas-but we can also expect a spike in domestic violence as tensions rise. Both contraceptive counselling and sensitive explorations of possible domestic abuse are likely to be affected by the loss of normal GP appointments and a switch to remote consulting.

On the positive side, there are already signs of "good neighbour" groups setting up all over the country, where people reach out to help others stuck at home by shopping, collecting prescriptions, and offering company by phone. We may rediscover the importance of the physical communities we live in-offering help, accepting help, interacting more. While we observe social distancing, we may paradoxically become closer as a society.

I admit that I'm scared. I'll try not to let that show in front of patients and colleagues, but I won't be taking this "on the chin." I'll do everything I possibly can to limit infections and keep the people around me safe. We all need to keep our eyes open for colleagues who are struggling, and each of us is likely to need support in the months ahead. We'll also need laughs, virtual hugs, and coffee.

Competing interests: See www.bmj.com/about-bmj/freelance-contributors. Provenance and peer review: Commissioned; not externally peer reviewed. Published by the BMJ Publishing Group Limited. For permission to use (where not already granted under a licence) please go to http://group.bmj.com/group/rights-licensing/ permissions 